\title{
Teoría del discurso y paradigmas arqueológicos
}

\author{
Theory of discourse and archaeological paradigms
}

\author{
Víctor M. FERnández MaRTínez \\ Departamento de Prehistoria \\ Universidad Complutense de Madrid \\ victormf@ghis.ucm.es
}

Recibido: 30-08-2012

Aceptado: 18-10-2012

\begin{abstract}
RESUMEN
Se presenta una revisión de la teoría y metodología actuales de análisis del discurso, tanto general como más concretamente de los discursos político y cientifico, optando por la posición postestructuralista de la "teoría del discurso" de Ernesto Laclau y la "Escuela de Essex". Tras analizar las posturas teóricas de la arqueología española actual, se hace un "análisis de contenido" cuantitativo de cuatro artículos en castellano, representativos de los paradigmas teóricos actuales más extendidos. Empleando la idea lacaniana de los "puntos nodales" (point de capiton) que dan sentido a los discursos, se advierte cómo los paradigmas más empiricistas (procesualismo, marxismo) necesitan de una mayor fijación del sentido de sus significantes (por los puntos nodales de "economía" y "producción") que los paradigmas estructuralista y posprocesual, los cuales admiten una mayor dispersión temática e indeterminación de los significantes.
\end{abstract}

Palabras Clave: Discurso arqueológico. Paradigma arqueológico. Análisis de contenido. Punto nodal. Laclau.

\begin{abstract}
A theoretical survey is presented of the current theory and methodology of discourse analysis, focusing on the political and scientific discourses. The present paper is explicitly ascribed to Ernesto Laclau's and the Essex school's poststructuralist 'theory of discourse'. After a short introduction to the recent theoretical positions in Spanish archaeology, a quantitative 'content analysis' is made of four theoretical papers written in Spanish. The application of the Lacanian 'nodal point' (point de capiton) analysis to the texts shows that the more empiricist paradigms (processual and Marxist) need their signifiers to be more strongly fixed (through the nodal points 'economy' and 'production') than the structuralist and post-processual discourses, which allow for a greater thematic dispersion and flotation of meanings.
\end{abstract}

KeY words: Archaeological discourse. Archaeological paradigm. Content Analysis. Nodal point. Laclau.

Sumario: 1. Introducción. 2. Análisis y Teoría del discurso. 3. El análisis del discurso arqueológico. 4. Corrientes teóricas en la arqueología española actual. 5. Análisis de discursos teóricos. 6. Conclusiones. 


\section{Introducción}

El presente trabajo intenta aplicar a la arqueología algunos de los desarrollos habidos últimamente en el campo del análisis del discurso, que forma parte del terreno más general de la lingüística aplicada. Impulsados por la importancia capital otorgada a los textos tras el giro lingüístico producido en las ciencias sociales y humanas por el auge del estructuralismo y movimientos posteriores y afines, los análisis del discurso enfocan una amplia gama de producciones, desde una simple conversación hasta la ideología sustentadora de un orden social, partiendo de la base de que siempre se trata de combinaciones de palabras en un orden admisible y en cierta forma determinado cuya estructura merece la pena analizar.

De la importancia del análisis del discurso en general da idea el número de manuales publicados y las revistas dedicadas al tema, que se han multiplicado en los últimos años. En un reader aparecido en 2001 (Wetherell 2001: 381) se citaban únicamente dos revistas, mientras que hoy en la base de datos Scopus se listan siete publicaciones periódicas en cuyo título aparece la palabra, y 97 que contienen el término "lenguaje", muchas de ellas dedicadas específicamente al uso social del lenguaje, es decir al discurso.

Como veremos, los estudios del discurso arqueológico han sido muy escasos hasta la fecha. Ello puede ser debido, por un lado, al fuerte componente positivista de nuestra disciplina, en la que constituyen una gran mayoría quienes implícitamente creen que el lenguaje es una imagen suficientemente fiel de la "realidad". Según esto, dedicarse a su disección, tarea para la que además la mayoría de nosotros no contamos con la preparación adecuada, es poco más que una pérdida de tiempo. Por otro lado, la tendencia dominante en el análisis del discurso, incluido el discurso científico, es también positivista con un fuerte componente descriptivo. De ahí que sus resultados muchas veces nos parezcan triviales y por ello incapaces de despertar el entusiasmo necesario para adentrarse en una nueva rama de la investigación.

Con todo, existe una línea de trabajo de carácter "crítico" que busca desentrañar los mecanismos no obvios del lenguaje y las diferentes alternativas de comunicación existentes, cuya elección implica una toma de postura política. A la rama del "análisis crítico del discurso", de inspiración marxista y ya fuertemente consolidada, se ha unido en los últimos años la autodenominada "teoría del discurso" de orientación postestructuralista pero que igualmente se reclama heredera avanzada de la vieja crítica materialista.
El presente trabajo pretende ser una primera aproximación al tema en la arqueología española, abordando cuatro textos teóricos correspondientes a las cuatro tendencias principales actuales mediante la técnica cuantitativa del "análisis de contenido" y analizando los resultados con los postulados de la teoría del discurso. El intento es consciente de sus limitaciones, tanto metodológicas como empíricas, pero espera aportar un cierto plus de autoconciencia y control de la subjetividad en la disciplina, siempre en el camino continuo de incremento de su propia madurez y utilidad como ciencia social.

\section{Análisis y Teoría del discurso}

La rama del análisis del discurso que podemos definir como más tradicional o positivista (corriente "formalista", "pragmática", etc.), representada por ejemplo en el manual traducido de Brown y Yule (2005), tiene por objetivo responder a las preguntas de para qué utilizamos el lenguaje y cuáles son las formas que éste adopta para conseguir unos fines particulares ("competencia lingüística"). Estos fines se resumen en conseguir la trasmisión de un mensaje a oyentes y lectores, pero las características de ese mensaje y sus intenciones últimas son dejadas de lado. No obstante, a pesar de concentrarse exclusivamente en los textos emitidos y en toda su complejidad (técnica, contexto, coherencia, conocimiento extra-discursivo, etc.), desde el inicio del análisis es evidente que su comprensión necesita muchas veces de algo que está fuera del texto. Por ejemplo, cuando se lee la descripción de un restaurante, es posible que esta palabra concreta no aparezca escrita y el lector la tenga que inferir a partir de otros elementos (mesas, platos, etc.): lo interesante es que solo a partir de esa inferencia el texto completo adquiere su sentido. Otro buen caso es el comienzo de la novela El sonido y la furia, de William Faulkner, donde se describe un campo de golf a través de sus aspectos parciales y solo cuando se avanza en la lectura se descubre cuál es el "tema" del que se trata y el conjunto de la historia aparece claramente (Ibid.: 244-5). También es curioso que ese asunto, que viene a englobar al discurso en su conjunto, no sólo sea esencial para entender el texto sino también para recordarlo: rememorar el comienzo de esa novela conllevará siempre aferrarnos a esa unidad simple que lo condensa (el campo de golf), que es su tema o su "título". Como veremos enseguida, este aspecto de la realidad del discurso será luego muy importante en el argumento teórico que utilizaremos como base de este trabajo.

Desde la década de 1970, y cristalizando después durante los años 1990, ha cuajado una escuela di- 
ferente de análisis textuales, el "análisis crítico del discurso" (CDA por sus siglas en inglés). Partiendo de las posturas de marxismo crítico de la Escuela de Frankfurt, y con los trabajos seminales de Van Dijk (2009), Fairclough (1995), Wodak y Meyer (2001), etc. -casi todos ellos profesores de universidades europeas y que han publicado sobre todo en la revista Discourse and Society-, la escuela trata de superar la mera descripción de los textos y entrar en los cruciales temas de la responsabilidad, los intereses y la ideología. El discurso deja de verse como un producto individual y se aprecia como un producto social, un lugar donde la persona hablante se ve inmersa. Como suele ocurrir cuando las ciencias sociales enfocan la actividad humana desde la perspectiva del grupo, no tardan en aparecer en la imagen las diferencias e injusticias internas, lo que no pocas veces provoca una toma de postura "política" por parte de los investigadores a favor de la parte más desfavorecida de la sociedad. Por ello el CDA analiza sobre todo los discursos del poder, la forma en que "la lengua es un medio de dominación", delatando la forma en que presenta esa misma dominación como algo "natural" e inevitable. Una consecuencia de lo anterior es que los discursos son obras colectivas que funcionan como escenarios de lucha donde diferentes ideologías contienden por la dominación (Wodak 2001: 11). De su método de análisis nos interesan dos aspectos que tendremos en cuenta en este trabajo: la selección de textos (fragmentos de discursos) que se consideren prototípicos del sector que se quiere analizar, y la localización de temas simples o términos que sean asimismo relevantes para el estudio (Jäger 2001: 54-55).

Lógicamente, una gran parte de la anterior corriente crítica se ha basado en la obra de Michel Foucault (1926-1984), creador en cierta medida del concepto actual de discurso. Como es sabido, el pensamiento de Foucault pasó por dos fases, en cierta medida complementarias, la "arqueológica" (años 1960) y la "genealógica" (décadas de 1970 e inicios de 1980) (Howarth 2000: 48-84). Mientras que la primera es más radicalmente estructuralista, la segunda tiene más en cuenta la historia y la influencia de la agencia humana en el discurso. Lo primero que Foucault hizo, al igual que antes había hecho Lévi-Strauss, fue rechazar como punto de partida el "humanismo" que cree en el sujeto como origen y fundamento del pensamiento y el discurso (fenomenología, existencialismo, etc.). Como dijo Heidegger en una de sus frases famosas, al entrar en sociedad el ser humano "es arrojado dentro del discurso", que existe previamente y que le conforma como sujeto mismo. Los discursos no solo "crean" los objetos que nombran, sino que el propio pen- samiento personal es producto del universo discursivo que lo rodea. Lo que distingue a Foucault del estructuralismo clásico (y lo hace ya "postestructuralista") es advertir el carácter histórico y cambiante de ese discurso (rechazo del esencialismo de las "estructuras" inmutables de la mente humana). De aquí lo absurdo de la usual acusación al postestructuralismo de subjetivismo, cuando lo que hace esta corriente es eliminar prácticamente al sujeto. Cada ser humano piensa de una manera diferente, pero todas esas ideas son mayoritariamente copias o nuevas combinaciones de ideas anteriores, que expresan su "posición de sujeto" en el campo discursivo y social. Tampoco tiene sentido la etiqueta de idealista, por cuanto se niega la separación entre el mundo discursivo y el material, que solo se explica en función del primero.

En su fase genealógica, representada sobre todo en su magna obra sobre la historia de la sexualidad, Foucault (1978) advierte el papel de los discursos en las estrategias y luchas de poder (de aquí su famoso binomio saber/poder). La acción humana no solo utiliza sino que crea contra-discursos que canalizan la resistencia ante la dominación. Frente al anterior concepto de "episteme" (reglas sobre lo que se puede pensar y decir en un momento histórico dado), Foucault propone ahora el de "dispositivo", conjunto heterogéneo de discursos, organismos, leyes, formas arquitectónicas, etc. con cuyo estudio se puede entender el origen histórico de las prácticas e instituciones. Al introducir elementos no discursivos en su argumento, este segundo período de Foucault representa en cierta manera un retroceso en la progresiva "textualización" inaugurada poco antes por el estructuralismo.

La posición más extrema en ese proceso la representó, como es bien conocido, Jacques Derrida (1930-2004), para quien no solo los seres humanos sino también las relaciones sociales y las instituciones materiales son un efecto de ese "sistema de diferencias" que llamamos lenguaje. A pesar de la indudable efectividad de su método deconstructivo de los discursos, a muchos autores la filosofia derridiana, que reduce los agentes sociales a meras consecuencias de las trazas y signos lingüísticos, el poder y la opresión a oposiciones binarias entre conceptos, las estructuras sociales a textos indecidibles, etc., les parece cuanto menos pasada de tono. No obstante, en la historia de las ciencias sociales muchas concepciones que fueron tachadas de exageradas en su aparición demostraron posteriormente su utilidad por haber abierto puertas hacia nuevas comprensiones de la realidad hasta entonces insospechadas.

Como una variante de la corriente del análisis crítico, adoptando algunos de los postulados más 
radicales del postestructuralismo, está la que suele recibir el nombre más específico de "Teoría del discurso" (Discourse Theory), postulada en principio por el argentino Ernesto Laclau y la belga Chantal Mouffe y hoy seguida por una serie de discípulos, en su mayoría pertenecientes a la universidad inglesa de Essex ("Escuela de Essex"): David Howarth, Aletta Norval, Yannis Stavrakakis, Oliver Marchart, Simon Critchley, Jason Glynos, etc. El propio Laclau reconoce que el origen de sus ideas estuvo en las intensas luchas políticas del Buenos Aires de los años sesenta, durante las crisis revolucionarias del peronismo que provocarían los golpes militares poco después. Partiendo de posiciones marxistas clásicas, Laclau enseguida vio que la perspectiva exclusiva de clase, y el consiguiente reduccionismo económico, habían de ser superados para poder hegemonizar a los variados movimientos políticosociales que surgían entonces en defensa de las capas sociales inferiores (en la línea de Antonio Gramsci), comprobando algo más tarde que la base teórica de ese cambio estaba en las entonces novedosas publicaciones de intelectuales como Derrida o Lacan (Laclau 1993: 207-210; Critchley y Marchart 2004b: 2).

Tras su exilio en Inglaterra (a donde fue llamado por Eric Hobsbawn), Laclau publica, con su mujer Chantal Mouffe, Hegemonía y estrategia socialista (1985, en español en 1987), el libro que anunció el nacimiento de lo que algunos llaman "posmarxismo" o marxismo postestructuralista. A pesar de las duras críticas que recibió desde posiciones clásicas, su influencia fue creciendo con publicaciones posteriores (nunca demasiadas) y en Essex creó una escuela de trabajos orientados sobre todo al análisis del discurso político. Dentro de esta corriente se han publicado compilaciones como Discourse Theory and Political Analysis (Howarth et al. 2000), Laclau. A critical reader (Critchley y Marchart 2004a), un manual universitario sobre el tema (Howarth 2000) y un tratado que sistematiza las bases teóricas de la "lógica de explicación crítica" en ciencias sociales y políticas defendida por esta escuela (Glynos y Howarth 2007).

En comparación con las tendencias dominantes en análisis del discurso, y apuntándose a las posturas derridianas, esta teoría no establece diferencias entre prácticas discursivas y no discursivas, pues cualquier actividad o producto humano se puede enfocar como discurso al ser de esa forma como es entendida y adquiere "sentido" para nosotros. Para esta radical perspectiva, es precisamente porque los sistemas de significado son contingentes y nunca pueden abarcar los campos sociales significativos por lo que son posibles las prácticas sociales y la política en cuanto tal; es decir, el conjunto de pro- cesos de construcción y contestación discursivas que constituyen por sí mismos la realidad social. A diferencia del análisis crítico-marxista clásico, que conserva una postura epistemológica realista -manteniendo teóricamente la separación entre el mundo real y el discurso-, y materialista -defendiendo la primacía de la esfera económica sobre la superestructura ideológica-, la escuela de Essex sigue decididamente el camino abierto por el primer Michel Foucault al concentrarse exclusivamente en las "formaciones discursivas", esa "textura argumentativa" que no solo da sentido sino que, a los efectos prácticos, crea la realidad (Wetherell 2001: 389-392).

Para la escuela de Essex todos los campos discursivos, precisamente por tener su origen en un sistema arbitrario de signos como es el lenguaje, están afectados por una contingencia radical, y en el terreno de lo social eso se traduce en la famosa afirmación central de Hegemonía y estrategia socialista: no existe lo que llamamos sociedad como una entidad fija, sino que es algo que se va creando a través de los diversos discursos que compiten entre sí por alcanzar la hegemonía, por "aprehender" la esencia de lo social, sin conseguirlo nunca plenamente. Siguiendo en la misma línea, Glynos y Howarth (2007: 133-164) llaman lógicas a esos tipos discursivos, un concepto no muy diferente de los de "reglas del juego" o "parecidos de familia" de Wittgenstein, o los de "episteme", "régimen de verdad" o "dispositivo" de Foucault. Un ejemplo actual del uso popular del concepto es la extendida "lógica del mercado" o, en el campo académico, las "lógicas de la competencia, atomización, jerarquía e instrumentalización" que el thatcherismo introdujo primero en la universidad británica y que poco a poco se van extendiendo como una plaga por todas las universidades europeas (cf. Worthington y Hodgson 2005, y el número monográfico 47-1/2 de Critical Quarterly). Otra aplicación es el muy citado estudio de los analistas de Essex sobre la "lógica del Apartheid" en Suráfrica, la forma en que los afrikáners crearon todo un sistema de nuevas categorías discursivas para justificar la separación y explotación racial (Norval 1996).

La actividad fundamental en la formación de las lógicas discursivas es la articulación (término que en lingüística indica la dicotomía entre el tema concreto y el comentario sobre él en una frase), que Laclau redefinió como "la construcción de puntos nodales que fijan parcialmente el significado", lo cual es necesario porque los discursos son siempre parciales a causa de la "apertura de lo social" y el "constante desbordamiento de los discursos por la infinitud del propio campo discursivo" (p. ej. los discursos científicos están "subdeterminados" por 
los datos y "sobredeterminados" por las teorías). El concepto proviene de la teoría psicoanalítica de Jacques Lacan, que llamó point de capiton ("punto de acolchado o capitoné", los botones que se cosen en puntos equidistantes de los cojines o las colchas para evitar que el relleno se deslice de forma desigual), a esos significantes que se fijan a una serie de significados relacionados, que no varían aunque cambien éstos porque los engloban y explican. A veces identificados con los llamados "significantes vacíos" o "significados flotantes", los puntos nodales son términos privilegiados que vienen a dar sentido a todos los demás (p. ej. la palabra "comunismo" en las sociedades estalinistas -ver infra-, que daba un sentido nuevo y justificativo de todos los demás términos políticos, o su equivalente "libertad" en las sociedades capitalistas) (Laclau y Mouffe 1987: 119-131; Žižek 1992: 125-127, passim; Howarth y Stavrakakis 2000: 7-9).

Según vemos, la visión de la sociedad por esta teoría "posmarxista" ha sustituido la lucha de clases por la lucha de discursos que intentan alcanzar una posición hegemónica. Se parte de la base de que la sociedad no puede constituirse como totalidad y esto origina un antagonismo o negatividad intrínseca en su interior. Los diferentes grupos luchan por rellenar los "significantes vacíos" con significados de su propio interés, y por ejemplo empresarios y trabajadores entienden de forma muy diferente conceptos en apariencia fijos como "justicia" o "libertad", tratando de imponer su posición a los demás, hacer que solo exista una interpretación y que su punto de vista se convierta en hegemónico (es decir, aparente representar a la vez su interés y el de los elementos opuestos).

Quizás el punto más discutible de la teoría es la explicación del origen de los propios antagonismos: dejando de lado la idea básica del marxismo que lo coloca en los intereses económicos de clase, Laclau y Mouffe apuntan a la realización de la identidad de personas y grupos. Como agentes sociales, éstos son incapaces de alcanzar plenamente su identidad por la presencia de un "Otro", con intereses contrapuestos, que lo impide (Howarth 2000: 105-107). En un estudio sobre la oposición ecologista a la ampliación del aeropuerto de Manchester, Griggs y Howarth (2000) analizaron cómo los grupos contrapuestos construyeron sus discursos respectivos con el objetivo, oculto en cierto sentido tras el aparente de conseguir bloquear o construir la nueva pista, de realizarse en tanto que "ecologistas" o "emprendedores". Que el discurso en realidad "va antes" que los intereses materiales se aprecia en que éstos, en contra de la creencia más habitual, no son fijos y dados de antemano, sino que son construidos mediante la actividad de propaganda política y que un mismo sujeto puede situarse entre varios o cambiar de uno a otro en función de aquélla (Ibid.: 55-56).

En el proceso discursivo, la propia actividad de "nombrar" algo constituye una actividad política. Siguiendo al filósofo Saul Kripke, Laclau concluye que la identidad y unidad de un objeto resultan del propio proceso de su nombramiento y que al nombrar una cosa de nuevo la redescribimos, emancipándola políticamente de sus ataduras conceptuales unívocas: que las cosas se llamen de diferentes maneras implica que pueden ser diferentes, y en definitiva que la realidad social se puede cambiar (Laclau 1992: 16-17). En una reciente polémica de prensa en nuestro país sobre las propuestas feministas de uso de un lenguaje no sexista (iniciada en Bosque 2012) hemos visto con tristeza hasta qué punto la mayor parte del establishment académico sigue adoptando posturas eminentemente positivistas, y cómo muchos lingüistas consideran a la lengua simplemente como una mera descripción directa de la realidad. Solo uno de los ejemplos aportados por una defensora de la postura contraria arrojó un poco de luz sobre el tratamiento tradicional del tema: en una escuela, cuando llegó una profesora nueva y dijo que "los niños" levantaran la mano, solo lo hicieron los de sexo masculino, para sorpresa de la recién llegada, que se limitaba a emplear el "masculino genérico". Simplemente ocurría que en esa escuela se habían acostumbrado a que en las clases hubiera "niños" y "niñas". Un empleo diferente de las palabras había empezado ya a cambiar la realidad y su significado. Otro caso aún más célebre es la polémica sobre el término "matrimonio" aplicado a las uniones homosexuales, donde la posición conservadora abraza un esencialismo lingüístico claro al no admitir ningún cambio en el significado de la palabra

Con los ejemplos del párrafo anterior hemos entrado en el terreno de la crítica política dentro de la investigación científica, cuyos apartados prácticos pueden dividirse en normativos y éticos según Glynos y Howarth (2007: 193-199). Para los posmarxistas, la orientación normativa parte de su compromiso con la democracia, no solo la democracia formal que conocemos todos, sino una democracia más desarrollada, deseable y futura, "radical y plural". Para caminar en esa dirección es preciso elaborar discursos "contra-lógicos" en los terrenos donde la Derecha es hegemónica, y describir los fenómenos con las palabras y las lógicas progresistas, llenando los significantes vacíos con un contenido de justicia. Un ejemplo es la dominante "lógica de la atomización", que opone unos individuos a otros en la continua competencia por cualquier clase de recurso, y que se puede rebatir mostrando cómo las características que se atribuyen 
a los individuos particulares (falacia del "psicologismo") son de hecho sociales y no solo comunes a mucha gente, sino que tienen un origen exterior y no han sido libremente escogidas. El sentido ético de la crítica está representado por la esencia del propio análisis postestructuralista: si no existen verdades absolutas, tampoco existen las que nos quiere imponer la ideología dominante, que históricamente se presentaban como producto de la revelación divina y hoy se disfrazan de resultados científicos, igualmente irrefutables. Aunque con frecuencia se ha acusado al posmodernismo teórico de provocar la inacción política, precisamente por la "indecidibilidad" e inestabilidad que desvelan en todos los conceptos, es precisamente de ahí de donde surge su fuerza ética: la apertura de lo social es lo que hace posible la creación de sociedades nuevas (que a su vez serán contestadas en el futuro, empezando de nuevo el ciclo crítico).

\section{EI análisis del discurso arqueológico}

Desde hace unos años existe en filología un campo de estudio llamado "análisis de discursos especializados" (specialized discourse analysis) o de "géneros especializados" (specialized genres), que cuenta ya con un cierto número de publicaciones internacionales (p. ej. Halliday 2004; Gotti y Giannoni 2006, Flowerdew y Gotti 2006; Bhatia y Gotti 2006 , etc). Como estudios concretos se pueden citar trabajos dedicados a analizar el lenguaje de la biotecnología, sobre la que existe bastante bibliografía (Doolin 2007), el lenguaje usado en las evaluaciones de artículos científicos (Ventola y Mauranen 1992), los textos empleados en los resúmenes de esos artículos (Phuong 2008), la relación entre los discursos científicos y los divulgativos (Koskela 1997) o entre los discursos empleados por los científicos y por los ecologistas (Doolin 2007), o comparando los textos que se basan más en datos empíricos o más en conceptos teóricos (McDonald 1989). Otro tipo frecuente de análisis consiste en cuantificar el uso de los términos y de otros rasgos gramaticales (gramática funcional o "análisis de contenido", content analysis), lo que es posible procesando mediante ordenador gran cantidad de textos, por ejemplo en ciencias sociales (Franzosi 2004) o en los textos divulgativos científicos (Oliveira y Pagano 2006). Para la presencia de este tipo de análisis en historia contemporánea ver Martin y Wodak 2003.

En muchos de esos estudios la retórica de los discursos, su empleo de los diferentes tropos gramaticales, en especial del principal de ellos, la metáfora, constituye una parte fundamental. Es un hecho que ningún lenguaje podría existir sin metáforas, lo que se comprende teóricamente recordando que no existe una relación directa entre palabras y cosas (por lo que las primeras tienen todas un origen metafórico) y se citan con frecuencia trabajos clásicos que describen la formación y funcionamiento de las metáforas en las cadenas del habla y el propio pensamiento diarios (p. ej. Lakoff y Johnson 2001). Su análisis en el lenguaje científico abre insospechadas percepciones sobre la forma en que trabajan los investigadores, incluso en las disciplinas en principio consideradas más rigurosas. Por ejemplo, antes de que Newton aplicara la palabra "fuerza" a sus leyes gravitatorias, el término se refería únicamente a la capacidad de violencia en los conflictos humanos, aunque hoy la aceptamos sin problema como expresión de la atracción que existe entre los cuerpos dotados de masa (concepto mismo, el de la gravedad -otra buena metáfora-, cuyo carácter último sigue sin ser comprendido por la Física contemporánea) (Ahmad 2006). En el caso de la Biología molecular un concepto clave es el de "traducción", entre los genes y las células, y entre unas y otras células, un significante que inicialmente sólo se empleaba para designar las traslaciones entre textos de diversas lenguas o en el campo general de la comunicación humana (Ibíd.). Incluso en la Física atómica actual no existe alternativa (en el lenguaje normal, otra cosa distinta es el matemático) al uso metafórico del lenguaje, como cuando se habla de fuerza nuclear "fuerte" y "débil", o cuando se nombraron los quarks porque el concepto recordaba al graznido de una gaviota, siendo el escritor James Joyce quien primero había usado una palabra muy parecida en uno de sus libros (Finnegans Wake)... (Ibíd.). En un campo más próximo a nosotros como es la teoría evolutiva, muchos de cuyos conceptos hemos tomado prestados en arqueología, el mismo Darwin utilizó con frecuencia una metáfora proveniente de la industria, la "división del trabajo" que realizan las diferentes partes de un organismo, y también tienen un origen metafórico externo otras expresiones características del darwinismo, como "lucha por la existencia", "selección natural", "código genético", etc. (Ruse 2009: 23-24).

En arqueología se han señalado las metáforas de la excavación arqueológica como una campaña militar, por supuesto masculina (frente a otras menos androcéntricas en las que se contempla la excavación como algo parecido a la agricultura), u otras metáforas obtenidas del mundo de los cowboys americanos; la del arqueólogo como artesano o "tejedor" que va componiendo su discurso desde diferentes fuentes (Joyce 2002), mientras otros estudios, en la onda de los trabajos sobre la historia de Hayden White (1992), han señalado los paralelos con las narrativas literarias (romance, comedia, tra- 
gedia), por ejemplo en la interpretación de los orígenes de la agricultura (Rudebeck 1996; Pluciennik 1999).

Relacionada con la metáfora está también la práctica de utilizar términos procedentes de otras ciencias para esclarecer fenómenos de una disciplina diferente (el concepto de "heteroglosia" introducido por Mikhail Bakhtin, ver Joyce 2002: 10). En arqueología se han utilizado conceptos procedentes de muchas otras ciencias: antropología, geología, biología, estadística, lingüística, literatura, etc. En los últimos decenios hemos visto cómo se impusieron primero las formas lógicas de argumentar de las ciencias duras con el surgimiento de la Nueva Arqueología (dinámica de sistemas, modelos de simulación, arqueología espacial, estadística, etc.) que continúan influyendo hasta nuestros días a través de otras inspiraciones naturalistas hoy en boga (sociobiología, psicologia evolutiva, filogenética cultural, etc.), pero que muy pronto fue contestada desde las formas más narrativas del paradigma posmoderno (estructuralismo, hermenéutica, fenomenología, etc.). Sin embargo, se ha avanzado poco en el estudio de los discursos arqueológicos, de sus diferentes paradigmas y tendencias investigadoras, desvelando las lógicas que intervienen y gobiernan sus textos, deconstruyendo sus contradicciones internas y sus sistemas ocultos de dominación, criticando las metáforas más habituales, descubriendo los significantes claves o puntos nodales que ayudan a dar sentido a todo el aparato discursivo, etc.

Uno de los primeros análisis de los discursos arqueológicos fue el realizado por Chris Tilley (1989a) a partir de las lecciones inaugurales de la cátedra Disney de Arqueología en Cambridge, desde su creación a mediados del siglo XIX hasta ese momento. Aunque el estudio no va mucho más allá de conocer con cierto detalle un género particular en sus aspectos formales (continuidades, referencias, auto-citas, uso de la primera persona, etc.), es interesante por mostrar uno de los "lugares" más poderosos desde donde se puede hablar en arqueología con la seguridad de que los discursos serán aceptados por la mayoría, casi con total independencia de lo que se diga.

Poco después, el mismo autor (Tilley 1990) volvió al tema fijándose en la forma general de escribir de los arqueólogos, imaginando un escrito autobiográfico de un profesional norteamericano que observa en un corto espacio de tiempo cómo cambian los temas y términos fundamentales de la disciplina (Ciencia, científico, laboratorio $\rightarrow$ sistema, economía, espacio, optimización, eficiencia $\rightarrow$ modos de producción, contradicción, sistema mundial $\rightarrow$ símbolo, estructura, ideología, polisemia, etc.). Después analiza la escritura de dos eximios representantes del procesualismo, L.R. Binford y M.B. Schiffer, su repetición insistente de ciertos términos (sobre todo el de "ciencia"), su gran cantidad de auto-citas, en definitiva su aserción del poder académico en cada fragmento de sus textos (para un análisis aún más detallado de "las estrategias de reproducción del prestigio en el discurso arqueológico" ver Hutson 1998). Entre otras cosas, Tilley (1990: 148) recomienda una aproximación humorística a los textos arqueológi$\cos$, idea que fue desarrollada por otros autores en varias publicaciones posteriores (Sillar 1992; Fernández 1997).

De nuevo, Chris Tilley (1993) realizó un estudio de los prospectos que anunciaban los departamentos de arqueología británicos, buscando con sentido del humor las afirmaciones más llamativas que se hacían para atraer a los futuros estudiantes y concluyendo que el pasado no era ni mucho menos el tema más importante de los textos, casi todos ellos centrados en el poder y prestigio de las instituciones académicas en el presente. En la misma obra colectiva, Julian Thomas (1993) examinó el uso del término "Neolítico" en obras representativas desde finales del siglo XIX hasta la actualidad. El inquietante resultado es que la palabra ha ido cambiando de significado a lo largo del tiempo (como cabría esperar de un fenómeno cultural tan largo y complejo) y, en consecuencia, que hacemos mal cuando leemos obras antiguas e interpretamos lo que dicen desde el contexto actual (habitualmente para reafirmar nuestras propias opiniones).

En la línea del trabajo de Thomas, Tilley realizó otra aproximación, dentro de una obra general sobre metáforas de la cultura material, al uso del término "megalitismo" desde el siglo XIX hasta el presente (Tilley 1999: 82-101). Tras un recuento del empleo del término y de su asociación con otros conceptos (arte, arquitectura, tiempo, muerte, ritual, etc. hasta 151 términos distintos), concluye que es una "metáfora congelada" cuyo significado se toma por literal, lo cual aproxima los textos arqueológicos a los literarios. En un sentido contrario a Thomas, comprueba que las mismas ideas, desde Montelius a Hodder, han reaparecido una y otra vez y en distinta forma a lo largo del tiempo.

\section{Corrientes teóricas en la arqueología española actual}

Aunque abordado relativamente por pocos autores (Anfruns et al. 1988; Martínez Navarrete 1989, 1993, 2002; Alcina 1991; Díaz-Andreu 1993; Ruiz Rodríguez 1993; Ruiz Zapatero 1993; Vicent 1994; Gilman 1995), el desarrollo teórico de la arqueo- 
logía española en los últimos años no ha estado ausente de nuestras preocupaciones investigadoras.

Como de forma clara expuso J. Vicent (1994), la arqueología española surge a comienzos del siglo XX de dos fuertes influencias exteriores: la escuela francesa en los estudios de Paleolítico y la escuela alemana para la Prehistoria reciente y la Protohistoria. La primera concibe el trabajo arqueológico según una metáfora orgánica (los “tipos" arqueológicos son como las especies biológicas dentro de los phyla evolutivos), tiene al paso del tiempo como principal referente de la variabilidad cultural y considera la taxonomía como la labor fundamental de nuestra profesión. La segunda proviene sobre todo de la obra del arqueólogo alemán ultranacionalista Gustav Kosinna y busca por encima de todo distinguir a los "pueblos" antiguos, identificados por su cultura material específica y que actuaron históricamente unos sobre otros a través de emigraciones e invasiones. Además de esa influencia alemana, y en un sentido muy parecido, hasta nosotros también llegaron la escuela antropológica de los círculos culturales del Padre Schmidt de Viena y la escuela histórico-cultural de Franz Boas en la arqueología americana, de aquí que a esta extendida corriente se la conozca habitualmente por historicismo cultural.

Que las invasiones del pasado, tan queridas por el historicismo, hayan servido para justificar otras del presente (como el colonialismo en África, cf. Fernández 2001), no es más que una de las evidentes conexiones de esa tendencia teórica con el pensamiento conservador. Esta relación también se observa en las concepciones idealistas de los historiadores tradicionalistas españoles, que influyeron decisivamente en las ideas arqueológicas: "Las prehistorias de España escritas durante casi un siglo son recapitulaciones de las colonizaciones griegas o fenicias o de las invasiones árabes para explicar los aspectos llegados a la Península Ibérica desde el Oriente, y de los Tercios de Flandes para dar cuenta de los atributos exportados desde Iberia a Europa (p. ej. el Vaso Campaniforme para algunos)" (Gilman 1995: 3). Todavía están por estudiar en detalle las relaciones entre la arqueología española y el pensamiento conservador (en ocasiones ultra-conservador, como el caso del Marqués de Cerralbo) pero un simple vistazo a nuestra realidad historiográfica muestra que eran bastante profundas (Díaz-Andreu 2002; Fernández 2011)

Las dos corrientes descritas no permanecieron estáticas a lo largo del tiempo, y en los años sesenta y setenta del siglo pasado se enriquecieron con los métodos científicos que ya se venían utilizando en Francia y Alemania: sistemática de excavación, análisis físico-químicos, fechas radioactivas, etc. En los estudios paleolíticos empezaron a cobrar una importancia fundamental los análisis medioambientales, que algo más tarde se aplicaron a otros períodos arqueológicos. A pesar de estos avances, la arqueología española siguió siendo esencialmente empirista, con un cierto rechazo hacia las generalizaciones y las reflexiones metodológicas y teóricas. Tal como lo expresó A. Ruiz Rodríguez (1993: 307), la arqueología de los últimos decenios "se debate entre un historicismo de marcado talante idealista y un eclecticismo 'inocente' de fuerte tradición positivista". Otra opinión parecida la ofreció A. Gilman (1995: 3), refiriéndose a la situación de unos años antes: "un idealismo vulgar que converge fácilmente con el reduccionismo biológico"

Ahora bien, la transición democrática tras la muerte de Franco y la espectacular expansión del número de profesionales en la década siguiente de 1980 provocaron importantes cambios. Por un lado, fue un momento de efervescencia teórica y metodológica en los países anglosajones (dominio del procesualismo) y por otro, los arqueólogos importantes de la época permitieron -o no lo pudieron impedir al verse desbordados por las circunstancias- que sus alumnos y continuadores se apuntaran a las nuevas tendencias, aunque ellos mismos no cambiaran en nada su forma de investigar (Vicent 1994: 220). Aunque muchos de los cambios se presentaban como "metodológicos" (p. ej. VV.AA. 1984), es decir, con un barniz positivista que las visiones tradicionales tenían muy difícil rechazar, algunos de los nuevos trabajos partían ya de una base teórica diferente.

Resulta curioso que a pesar del gran empuje de la Nueva Arqueología en aquel momento, que llevó a que hoy sea este paradigma, ahora llamado Procesualismo, el dominante en todo el orbe anglosajón, su efecto real en la arqueología española fuera realmente pequeño, y lo siga siendo hoy día. Esto ocurrió a pesar de la traducción al castellano de varias obras capitales norteamericanas por iniciativa de arqueólogos americanistas como Miguel Rivera de la Universidad Complutense, ámbito donde la influencia de José Alcina, un "viejo maestro" que, a diferencia de la mayoría de sus coetáneos, quiso ponerse al día, impulsó toda una serie de trabajos procesuales que sin embargo tuvieron poca influencia entre los arqueólogos que trabajaban en la Península.

En España del procesualismo se tomaron mucho más los apartados metodológicos -como por ejemplo la estadística, que no era exclusiva de esta aproximación, y que ha tenido especial relevancia después en la arqueología catalana- que los teóri$\cos$, de corte funcionalista y sobre todo evolucionista. En esta última línea ha habido que esperar hasta hace poco tiempo, ahora ya por influjo de las co- 
rrientes neo-evolucionistas anglosajonas (O'Brien, Shennan, etc.), para ver contribuciones originales entre nosotros (García Rivero 2004; Escacena y García Rivero 2007)

Un apartado que se presentó bajo una apariencia metodológica pero estaba dotado de mayor profundidad, y donde la Nueva Arqueología tuvo una mayor influencia entre nosotros, sobre todo a partir del Reino Unido (D.L. Clarke, I. Hodder, C. Orton, etc.), fue la que entonces se llamó "arqueología espacial" y hoy se prefiere etiquetar como "arqueología del paisaje". En ese cambio de nombre ya se revela la transformación producida en su contenido, que pasó de ser procesual y funcionalista (primeros congresos de Arqueología Espacial organizados por Francisco Burillo en el Colegio Universitario de Teruel a partir de 1984) a abrazar el estructuralismo simbólico, por influencia de Felipe Criado y el grupo de la universidad y luego del CSIC en Santiago de Compostela (cf. serie de publicaciones CAPA y TAPA).

La arqueología espacial también influyó en la que fue la corriente renovadora teórica más importante de la transición en España, la arqueología marxista; influjo que fue más claro en los equipos andaluces (Ruiz Rodríguez, Molinos, Nocete, Castro, etc.) que en los catalanes (Lull, Estévez, Vila, etc.). Tal vez por sus relaciones con los arqueólogos marxistas latinoamericanos (la "arqueología social latinoamericana"), los representantes españoles de esta tendencia han seguido demasiado rígidamente los postulados del marxismo economicista clásico, y han sido, como clasificó en su día el norteamericano Randall McGuire, "arqueólogos de la Segunda Internacional", al estilo de P. Kohl o T. Patterson, muy poco orientados a lo simbólico como están en cambio los marxistas estructuralistas (M. Rowlands), los seguidores de la Escuela de Frankfurt (M. Leone) o los "hegelianos" como el mismo McGuire (McGuire y Navarrete 1999: 189). Hasta hoy, los cambios recientes del "posmarxismo" no han tenido apenas eco entre nosotros, salvo en algunas introducciones generales (Fernández 2006a: 77-86).

Por último, la influencia de los movimientos posprocesuales, a pesar del gran ruido que se ha armado, ha sido relativamente pequeña entre nosotros. La única excepción cuantitativa ha sido la arqueología feminista o del género que, si bien en ocasiones se ha considerado parte de la arqueología posprocesual en sentido amplio, es demasiado variada para ser integrada en ella sin entrar en matices. Por un lado, la crítica que los movimientos posmodernos en general dirigieron al positivismo científico en las ciencias humanas (naturalismo, evolucionismo, funcionalismo, etc.) contribuyó a que el feminismo levantara la cabeza en sentido epistemológico y dejara de ser un movimiento de tipo únicamente político-social. De hecho, uno de los principios más radicales del movimiento en su nueva vertiente académica, a veces llamado "del punto de vista" (standpoint), propone que las mujeres contemplan la realidad de un modo diferente y por ello producen un tipo de ciencia distinto (además de un nuevo tipo de relaciones humanas y de sociedad misma). Pero, por otro lado, ante la frecuente acusación de postura eminentemente política y no científica que el movimiento sufre desde la mainstream disciplinar, muchas arqueólogas feministas rechazan la integración en el posprocesualismo y paradójicamente reclaman para su posición un estatus de ciencia positiva universal que tiene difícil encaje con su intrínseca, y deseable sin duda, parcialidad.

No es muy diferente la también paradójica situación de la arqueología poscolonial, encerrada en el dilema de rechazar la primacía de los discursos occidentales y obligada a reconocer la ausencia, cuando no la misma imposibilidad, de un discurso alternativo y a confinar por tanto sus reclamadas nuevas ideas en los "viejos frascos" de las antiguas palabras. Pero tal vez estas contradicciones sean más aparentes que reales, o más beneficiosas que perjudiciales, y provengan de nuestra resistencia a abandonar viejos hábitos; como veremos al final del trabajo, en la lucha de las ideas y las palabras nos vamos moviendo, aunque no sepamos bien hacia donde, como un barco en medio de un mar agitado que todos debemos surcar sin remedio.

\section{Análisis de discursos teóricos}

Para esta aplicación práctica hemos elegido tres artículos de corte teórico escritos por arqueólogos españoles, además de un artículo traducido al castellano de Ian Hodder, que podemos considerar representativos de varias corrientes teóricas. El primero de ellos corresponde a los intentos iniciales de introducción de la Nueva Arqueología en España y consiste en una explicación sencilla del análisis de territorios arqueológicos, por entonces muy novedoso y que poco después se extendió con relativo éxito entre nosotros (Fernández y Ruiz Zapatero 1984). Que haya escogido un texto del que fui coautor no se explica solo por conveniencia y por la escasez de estudios teóricos en nuestra lengua, sino también por un esfuerzo de auto-extrañamiento que considero bastante saludable. El segundo es una reflexión teórica sobre el modo de producción tributario en la Protohistoria y constituye un buen ejemplo de ensayo de tipo marxista (Vicent 1998). El tercero es uno de los primeros trabajos de corte estructuralista, con algunos elementos ya postestructuralis- 
tas, aplicado al megalistismo del Noroeste (Criado 1989). Por último, se analiza el artículo que Hodder escribió de encargo como introducción al posprocesualismo en arqueología y que apareció dos años antes en la misma revista que el anterior (Hodder 1987).

El método seguido para analizar estos discursos es el conocido como "análisis de contenido" de tipo cuantitativo, realizando el recuento de los vocablos considerados teóricos en cada uno de los artículos anteriores. Por razones de tiempo y espacio, no hemos analizado las formas argumentativas o gramaticales, los sistemas de razonamiento u otros aspectos del discurso que son también de gran interés. Otro motivo de esa elección es la consideración de que todo texto científico, en especial si es de tipo teórico, exige el dominio de una serie de términos (un "lenguaje" específico) que constituyen la esencia de la corriente o paradigma al que se adscribe. Cualquier lector ilustrado es capaz de distinguir, por ejemplo, que la aparición de las expresiones "modo de producción" o "cultura arqueológica" en dos textos está indicando que el primero se adscribe probablemente al paradigma marxista y el segundo seguramente se puede catalogar como historicista. Por último, la teoría lacaniana que ya vimos sobre los "puntos-nodales" de un discurso, términos que tienden a fijar el significado de los demás, nos impulsó a dejar de momento de lado la sintaxis y concentrarnos en la semántica de esos trabajos.

En el recuento se escogieron aquellos términos abstractos que hacen referencia explícita a la explicación arqueológica, pero no aquellos más generales que aparecen en cualquier argumentación. También se discriminaron las palabras que pudieran tener más de un sentido: por ejemplo, "trabajo" solo se contó cuando se refiere al trabajo manual productor de riqueza, pero no a una publicación científica; igualmente, en el término "crítica" es preciso distinguir entre cualquier tipo de recriminación o corrección y la llamada "teoría crítica" general de la Escuela de Frankfurt, etc. Se han computado dentro del mismo término tanto el sustantivo como el adjetivo formado a partir de aquél. En ocasiones se han unificado vocablos que tienen un significado similar, por ejemplo "desigualdad" y "división social". Cuando un término aparece varias veces dentro de la misma frase en general se ha contado como una sola ocurrencia. El recuento se hizo manualmente o con la herramienta de "búsqueda avanzada" del programa Adobe Acrobat en caso de disponer del artículo en formato $p d f$.

En las tablas 1 a 4 se exponen los recuentos de los diferentes términos teóricos en los cuatro artículos analizados. Únicamente se han presentado los que aparecen como mínimo cinco veces en cada trabajo.

\begin{tabular}{|l|c|}
\hline TÉRMINO & $\mathrm{N}$ \\
\hline Economía & 26 \\
\hline Hipótesis/modelo & 17 \\
\hline Población/demografía & 15 \\
\hline Territorio & 14 \\
\hline Recursos & 13 \\
\hline Variable & 9 \\
\hline Captación & 9 \\
\hline Antropología & 9 \\
\hline Territorio de explotación & 9 \\
\hline Estacionalidad & 8 \\
\hline Movilidad & 7 \\
\hline Análisis & 6 \\
\hline Teoría & 6 \\
\hline Comportamiento & 6 \\
\hline Medio ambiente & 5 \\
\hline Capacidad sustentadora & 5 \\
\hline
\end{tabular}

Tabla 1.- Relación de términos teóricos y sus frecuencias en Fernández y Ruiz 1984.

\begin{tabular}{|l|c|}
\hline TÉRMINO & N \\
\hline Excedente & 27 \\
\hline Parentesco & 26 \\
\hline Modo de Producción & 25 \\
\hline Sociedad & 22 \\
\hline Clase social & 18 \\
\hline Explotación & 17 \\
\hline Estado & 16 \\
\hline Comunidad & 14 \\
\hline Historia & 13 \\
\hline Trabajo & 11 \\
\hline Capitalismo & 11 \\
\hline Reciprocidad & 11 \\
\hline Desigualdad & 10 \\
\hline Producción & 9 \\
\hline Medio de Producción & 9 \\
\hline Formación social & 9 \\
\hline Fuerzas productivas & 6 \\
\hline Antropología & 6 \\
\hline Contradicción & 6 \\
\hline Ideología & 5 \\
\hline
\end{tabular}

Tabla 2.- Relación de términos teóricos y sus frecuencias en Vicent 1998. 


\begin{tabular}{|c|c|}
\hline TÉRMINO & $\mathrm{N}$ \\
\hline Sociedad & 96 \\
\hline Espacio & 55 \\
\hline Cultura & 40 \\
\hline Pensamiento & 43 \\
\hline Función & 26 \\
\hline Poder & 24 \\
\hline Medio ambiente & 23 \\
\hline Ideología & 22 \\
\hline Simbolismo & 20 \\
\hline Naturaleza & 20 \\
\hline Paisaje & 20 \\
\hline Salvajismo & 19 \\
\hline Teoría & 18 \\
\hline Contexto & 18 \\
\hline Discurso & 16 \\
\hline Territorio & 12 \\
\hline Economía & 10 \\
\hline Antropología & 8 \\
\hline Producción & 8 \\
\hline División social & 8 \\
\hline Estructura & 7 \\
\hline Mito & 7 \\
\hline Modelo & 6 \\
\hline Subsistencia & 6 \\
\hline Significado/sentido & 6 \\
\hline Ancestros & 6 \\
\hline Historia & 5 \\
\hline Imaginario & 5 \\
\hline
\end{tabular}

Tabla 3.- Relación de términos teóricos y sus frecuencias en Criado 1989.

\begin{tabular}{|l|c|}
\hline TÉRMINO & N \\
\hline Significado/ sentido & 31 \\
\hline Estructura & 30 \\
\hline Simbolismo & 28 \\
\hline Sociedad & 23 \\
\hline Mente & 22 \\
\hline Teoría & 18 \\
\hline Contexto & 17 \\
\hline Mujer/género & 16 \\
\hline Interpretación & 13 \\
\hline Datos & 13 \\
\hline Ciencia & 12 \\
\hline Poder & 10 \\
\hline Cultura & 10 \\
\hline Subjetividad/relativismo & 9 \\
\hline Antropología/Etnografía & 7 \\
\hline Positivismo & 7 \\
\hline Ideología & 7 \\
\hline
\end{tabular}

\begin{tabular}{|l|l|}
\hline Texto/discurso & 6 \\
\hline Agencia & 6 \\
\hline Escritura vs. palabra & 6 \\
\hline Economía & 6 \\
\hline Ley & 6 \\
\hline Inconsciente & 5 \\
\hline Historia & 5 \\
\hline
\end{tabular}

Tabla 4.- Relación de términos teóricos y sus frecuencias en Hodder 1987.

Lo primero que llama la atención es el incremento del número de términos teóricos al pasar del procesualismo al marxismo, y de nuevo de éste al estructuralismo. De haber evaluado también un artículo historicista, hubiéramos sin duda observado también un incremento de "teoricidad" entre éste y el artículo procesual (claro que lo difícil es encontrar un trabajo historicista "teórico"). Entre otras cosas, lo anterior viene a confirmar esa cierta costumbre de usar el término simple de "teoría" para englobar todos los desarrollos posteriores al estructuralismo (aquellos que convirtieron "lo familiar en extraño" según Culler 1992: 14-15). La palabra misma se usa con cierta frecuencia en los trabajos estructuralistas analizados, mientras aparece en muchas menos ocasiones, o no aparece, en los otros dos.

Otra constatación curiosa es la escasa coincidencia de términos teóricos que se aprecia entre las tres tendencias, como si realmente trataran de temas completamente diferentes. Pero lo cierto es que no lo hacen, y que todos los artículos tratan de arqueología, es decir, de cómo interpretar a nuestros antepasados más lejanos a partir de sus restos materiales, pretendiendo además hacerlo del mejor modo posible. Tenemos aquí de nuevo la clásica constatación kuhniana de que, en contra de lo que muchos piensan, los paradigmas en ciencia no contradicen simplemente a los anteriores corrigiendo sus fallos sino que los "superan", colocando su enfoque en otros problemas y datos, es decir, "trabajando en un mundo diferente" (Kuhn 1971: 187) donde son necesarios nuevos conceptos y términos. También vemos aquí un ejemplo de la traída cuestión de la inconmensurabilidad de los paradigmas, que no son evaluables uno respecto a otro por referencia a ninguna instancia exterior que sirva de referencia de "verdad" o "realidad", como ocurre por ejemplo con una ley concreta de la física o la química. Esto no quiere decir que no se puedan comparar, porque sus identidades no están completamente selladas y se definen precisamente por su diferencia con otros discursos y paradigmas, únicamente que las afirmaciones de cada uno de ellos se realizan desde un 


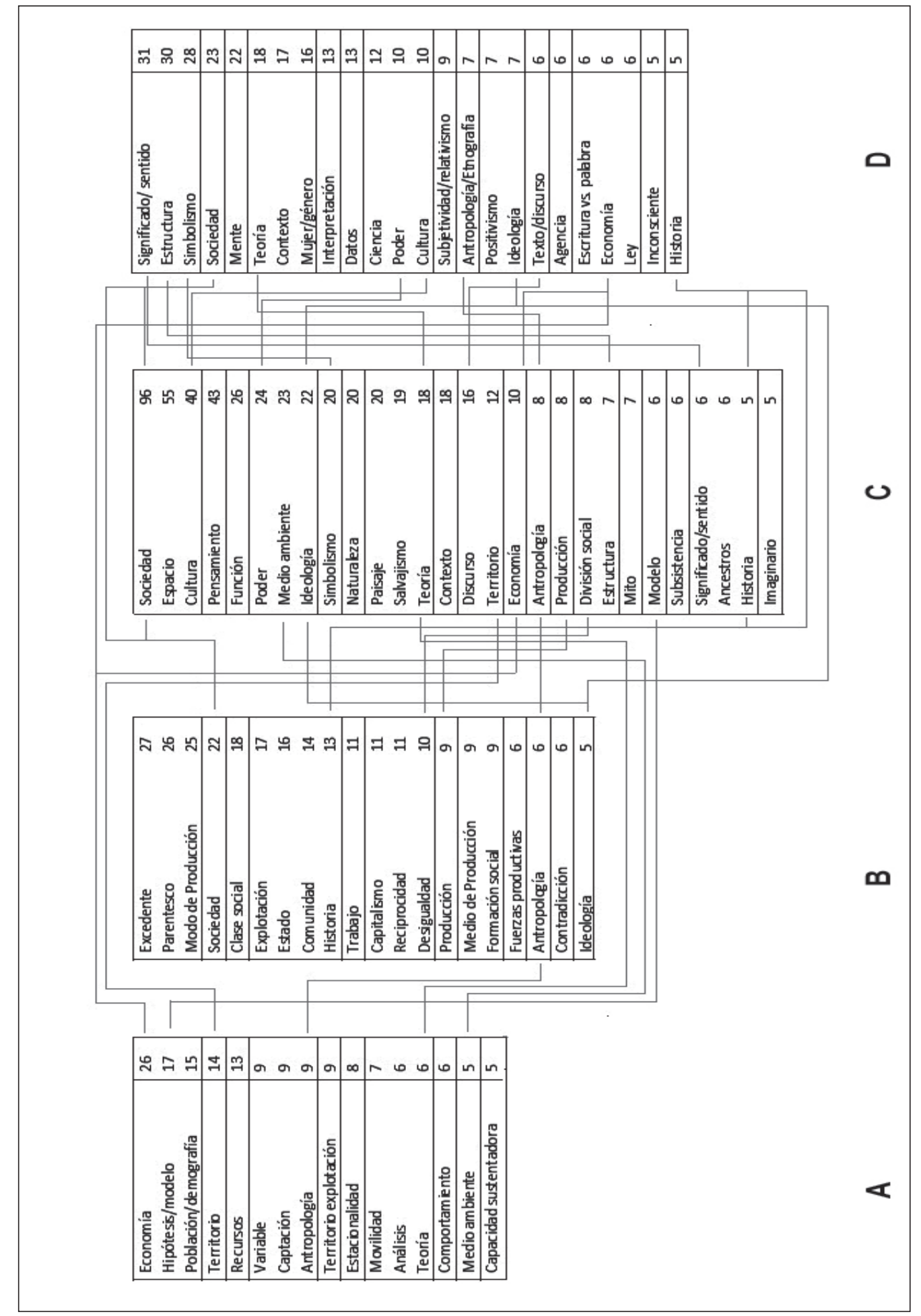

Figura 1.- Comparación de las cuatro tablas anteriores, correspondientes a los paradigmas procesual (A), marxista (B), estructuralista (C) y posprocesual (D), indicando los términos que son coincidentes entre unas y otras. 
conjunto concreto y distinto de significados y valores. Tampoco se desprende que unos no puedan ser "mejores" que otros, o que no se pueda cambiar de uno a otro con un sentido de superioridad o perfeccionamiento, sólo que ello se lleva a cabo a través de actos de persuasión o incluso de una "conversión" de los valores, como cuando a alguien se le "cae la venda de los ojos" (Kuhn 1971: 192-193; Howarth 2000: 114-115).

El único término teórico que comparten los cuatro paradigmas en los artículos analizados es el de "antropología" (o etnografía), como una especie de horizonte común o basal que está por encima de las diferencias de enfoque, que designa a otra disciplina diferente y en cierta medida "matriz", y por lo tanto está fuera del debate teórico en arqueología. Es interesante observar que su presencia proporcional más fuerte se produce en el texto procesual, marcando la importancia que tuvieron los paralelos antropológicos y la etnoarqueología en el origen de ese movimiento.

En la figura 1 se han colocado en paralelo las cuatro tablas, indicando mediantes líneas de unión los vocablos que son idénticos en los cuatro paradigmas (aunque no tengan el mismo significado en todos ellos, asunto sobre el que volveremos luego). Si para simplificar llamamos A, B, C y D a los cuatro enfoques (en el mismo orden en que están representados por las tablas), tenemos que entre A y B hay un solo término de unión (Antropología), entre A y C cinco (Economía, Territorio, Teoría, Medio Ambiente, Modelo; en lo sucesivo ya no mencionaremos Antropología), y entre A y D solo uno (Economía). Estas escasas relaciones sugieren un cierto "aislamiento" teórico de la arqueología procesual, cuyo funcionalismo economicista extremado (sobre todo en el caso concreto del análisis territorial; es significativo que en el texto A no haya prácticamente referencias a la "Sociedad") es probablemente la causa del rechazo que sus propuestas han sufrido finalmente entre los arqueólogos españoles y europeos en general. El mayor solapamiento de términos entre procesualismo y estructuralismo tal vez pueda explicarse por la postura del representante escogido para el segundo, que en varias ocasiones ha defendido un cierto eclecticismo teórico y mostrado una voluntad clara de permanecer dentro de la cientificidad clásica (Criado 2012: 124-127).

Si nos fijamos en el texto marxista (B), veremos que entre $\mathrm{B}$ y $\mathrm{C}$ hay cinco coincidencias (Producción, Sociedad, Historia, Desigualdad e Ideología); hemos considerado que el sentido de "producción" en ambos textos es muy parecido aunque el estructuralista no use nunca las categorías marxistas de "Modo de producción", "Fuerzas productivas", etc. Entre B y D el número de solapamientos es inferior, únicamente tres (Sociedad, Historia e Ideología). Nada hay aquí que se pueda añadir a lo ya sabido de la influencia del marxismo en el estructuralismo y sobre todo en el postestructuralismo; el mayor contacto en esta muestra con el primero puede estar también relacionado con el eclecticismo antes mencionado, o deberse a la importancia del marxismo en la arqueología española como primera teoría explícita a la cual había que responder. Por último, la coincidencia entre los textos C y D es la mayor de todas, como era esperable (11 términos, prácticamente la mitad en el caso de la muestra D). En su mayoría se trata de conceptos referidos al campo simbólico: Ideología, Simbolismo, Teoría, Discurso, Estructura, Significado.

Pero el resultado más esperado por nosotros a priori de esta comparación es el descubrimiento de un "tema" en cada una de las muestras discursivas elegidas. Si aplicamos la profundización y ampliación de ese concepto por los postestructuralistas, como vimos en el segundo apartado de este trabajo, nos interesa averiguar "de qué habla", "qué pretende" cada uno de estos textos; che vuoi?, como diría Žižek para el mismo análisis en el campo de la política (Žižek 1992: 125-175). Queremos comprobar si para cada paradigma se puede descifrar la existencia de uno o varios "puntos nodales" que "acolchen" y fijen el significado del resto de significantes de cada discurso. Porque, en palabras del mismo autor:

"El espacio ideológico está hecho de elementos sin ligar, sin amarrar, 'significantes flotantes', cuya identidad está 'abierta', sobredeterminada por la articulación de los mismos en una cadena con otros elementos: es decir, su significación 'literal' depende de su plus de significación metafórica" (Žižek 1992: 125).

El término propuesto seguidamente como ejemplo por Žižek, "Ecologismo", tiene el problema de que "su conexión con otros elementos ideológicos no está fijada de antemano" y así tenemos desde un ecologismo casi revolucionario (como los "ecoguerreros" de Greenpeace) hasta un ecologismo conservador ligado a la nostalgia de épocas pasadas. Por el contrario, el término "Comunismo" fijaba el sentido de toda una serie de términos en los llamados "países del Este": Socialismo (que allí era "real"), Democracia ("popular" en oposición a "formal" o "burguesa"), Ecologismo (por la ausencia del capitalismo contaminante, si bien finalmente resultó que el comunismo lo era mucho más), Feminismo (mediante la participación plena de las mujeres en la producción económica), etc. (Žižek 1992: 125-126). Por otro lado, la cadena de significantes nodales no se detiene y forma una jerarquía combinatoria realmente complicada: por ejemplo, aun- 
que políticamente poco definidos como acabamos de ver, los movimientos ecologistas se adscriben en su conjunto a una ideología política "Verde" (al igual que existe una política "Liberal") que otorga un significado común y actúa como punto nodal de toda una serie de movimientos dispares (Stavrakakis 2000: 101-102).

Aunque este tipo de análisis se ha aplicado a los campos sociológico y político, en tanto que productos intelectuales los discursos científicos, en especial los de las ciencias sociales y humanas, pueden ser también objeto de un idéntico escrutinio. Hace unos años intenté demostrar que no había diferencias epistemológicas esenciales entre el discurso político y el discurso científico social (Fernández 2006b). En un plano práctico, las divergencias se empiezan a borrar una vez se aprecia el absurdo del "mito de la ausencia de valores" que idealiza las ciencias como despegadas, objetivas y apolíticas, impidiendo de hecho cualquier crítica social y funcionando objetivamente como un apoyo al orden establecido (Tilley 1989b: 110-111). Por otro lado, tenemos que, al igual que las ideologías políticas, todo paradigma científico intenta apropiarse del universal presentándose como explicación general capaz de "suturar" la apertura y complejidad de lo real. En palabras de Laclau:

“... en otros tipos de ideología el módulo es similar [al de las ideologías políticas]. Un paradigma científico, por ejemplo, puede presentarse como encarnando la plenitud del principio puro de cientificidad. Una teoría científica, de tal modo, se torna ideológica cuando pasa a constituir un horizonte. El darwinismo es un buen ejemplo" (Laclau 2002: 21).

Si empezamos con el texto procesualista (Fernández y Ruiz 1984), observamos que la mayoría de los vocablos teóricos hacen referencia a la esfera económica, e incluso el mismo término de "economía" es el más empleado. No resulta difícil inferir un papel de punto nodal para ese mismo concepto, que sirve para fijar el sentido de muchos de los demás: territorio es el área cuyos recursos son explotados, la captación se refiere al flujo de materiales que llegan al yacimiento, estacionalidad y movilidad son formas de explotación del espacio geográfico, el medio ambiente se mide precisamente por su capacidad sustentadora alimenticia, etc. No viene de más recordar que esas palabras no tienen ese significado asignado previamente (todas ellas podrían querer decir otra cosa), sino que lo adquieren dentro del contexto del trabajo, dirigido por ese significante privilegiado que es "economía". Tampoco resulta extraño que las principales críticas a éste y otros métodos de prehistoria económica hayan resaltado la imagen reduccionista que proponen del ser humano como exclusivamente orientado a la consecución de comida, una especie de "estómago con piernas" (Dennell 1983: vii).

En el artículo de orientación marxista (Vicent 1998) no es difícil inferir que el punto nodal que "acolcha" el discurso casi en su totalidad es "producción". No solo por el número de expresiones que usan el término (relaciones productivas, modo y medio de producción, etc.) sino porque da significado a la gran mayoría de los demás vocablos. Empezando porque el propio término tiene un sentido muy específico en este paradigma, pues no solo indica el proceso de transformar la materia aumentando su valor sino de hacerlo dentro de un sistema de relaciones donde importa más quién fabrica, posee, vende y consume, se apropia de su plusvalía, etc. Como es sabido, un "modo de producción" tiene un sentido muy distinto de una "sociedad" o una "cultura", abarcando el modelo completo de relaciones económicas en su interior. Si elimináramos ese concepto del texto, no es exagerado decir que el discurso completo tendría otro sentido, o incluso que podría carecer de él por completo. Por otro lado, vocablos que también se emplean en otros tipos de discurso teórico (sociedad, explotación, estado, trabajo, desigualdad, contradicción, ideología) adquieren un significado muy preciso y diferente cuando se usan en un contexto discursivo marxista.

Por último, vemos que en los ejemplos estructuralistas resulta más difícil determinar la existencia de puntos nodales con un significado "privilegiado". En ambos textos predominan los términos relacionados con la propia significación, aunque son diferentes en cada uno: pensamiento/ideología en el primero frente a sentido/simbolismo en el segundo. Este carácter auto-reflexivo, tantas veces bordeando el meta-lenguaje, de los discursos estructuralistas es la causa de la incomprensión, cuando no la irritación, que producen en los lectores de formación positivista que se acercan a ellos. Ahora bien, el grado alcanzado de auto-conciencia es el producto lógico del giro lingüístico en las ciencias sociales, $\mathrm{y}$ aunque muchos puedan pensar que se trata de una moda pasajera algo extremada, pocos pueden dudar de que nada volverá a ser igual después del vendaval ontológico que ha provocado. No solo se trata del citado cambio de enfoque y datos de un nuevo paradigma, sino que hasta las aproximaciones más positivistas que puedan seguir existiendo en el futuro de las ciencias sociales tendrán que mirar con mucha más atención al lenguaje que utilizan.

\section{Conclusiones}

Recuerdo que mi primer interés por el discurso, aunque yo entonces no lo llamara de esta manera, 
fue precisamente cuando leí el artículo aquí analizado de J. Vicent sobre el modo de producción tributario (Vicent 1998). Aunque mi pelea teóricosemántica con el marxismo se remontaba a varios decenios atrás, mi entonces reciente acercamiento al postestructuralismo me hizo ver claro hasta qué punto adscribirse a un paradigma significaba en primer lugar el dominio de un nuevo léxico. Más tarde intuí también que todo ello puede tener como significado más profundo el deseo de alcanzar una identidad determinada. Veamos un ejemplo: ahora que vivimos en España una pasión relativamente extendida por el disfrute y conocimiento del vino, cualquiera que haya asistido a una cata especializada habrá advertido la importancia que tienen las palabras. Si alguien quiere alcanzar la identidad de conocedor o entendido en vinos debe pasar de decir, por ejemplo, que un vino concreto huele bien o tiene buen gusto, a usar expresiones como que tiene "buena nariz" o "buena boca". Igualmente será de mucho mejor tono hablar de "taninos astringentes" que limitarse a decir que un vino raspa o es fuerte. Con todo, que el tema de la identidad es más complicado de lo que aparece a simple vista lo podemos apreciar en que muchos enólogos, precisamente los de mayor categoría, tienden a emplear vocablos sencillos en sus intervenciones, como una forma de luchar contra ese marchamo negativo de esnobismo y "distinción" que afecta al vino en nuestro país y que para algunos es motivo de que su consumo masivo no acabe de despegar.

Pero tanto si se usan términos técnicos como sencillos, todos nosotros estamos determinados por los límites de nuestro propio lenguaje, dentro del cual "habitamos" y que nos restringe lo que podemos decir en cada momento impidiendo el desarrollo de una mayor "imaginación arqueológica" (Tilley 1999: 94-95). De ahí el interés de estudios en la línea del presente trabajo, que incrementen nuestra auto-consciencia como una forma de relativizar y cuestionar las propias creencias y también de posibilitar el cambio a nuevos y más fructíferos ámbitos teóricos y lingüísticos.

En su revisión del concepto clásico de ideología, tanto Žižek (1992; 1994) como Laclau (2002) niegan la posibilidad de una crítica a partir del concepto de "distorsión" (una generalización de la vieja idea marxista de la "falsa conciencia") que aparece siempre ligado a "ideología" (ver por ejemplo el conocido estudio de Eagleton 1997). Se supone que la distorsión ocurre entre el discurso y el ámbito extradiscursivo: por ejemplo, una ideología política conservadora se puede criticar si se denuncian los intereses concretos, a menudo económicos, a los que sirve y que están ocultos detrás de ella. Pero, como hemos quedado en que la economía también perte- nece al ámbito discursivo, esa distorsión "externa" no es real (de hecho, la mayoría de los conservadores conocen esa realidad y no suelen cambiar por ello de ideología). La verdadera distorsión, la "ilusión ideológica por excelencia”, proviene de creer que existe un punto de vista metalingüístico, una "realidad que habla sin mediaciones discursivas" y que puede zanjar el problema de la confrontación de ideas que constituye la "irreductible apertura" de lo social. Esto no quiere decir que no se pueda hacer crítica ideológica, solo que siempre se hará desde dentro de la ideología, nunca desde un lugar exterior privilegiado que no admita réplica, porque "todos los discursos que organizan las prácticas sociales están al mismo nivel y son, a la vez, inconmensurables unos con otros" (Laclau 2002: 12).

¿Ocurre algo parecido en el terreno de la ciencia? ¿No se parece lo anterior, al menos en las ciencias sociales, a la inconmensurabilidad de los paradigmas, la incapacidad de criticarlos desde fuera, la elección que hacemos de cada uno de ellos por razones extra-científicas o cuando menos difícilmente objetivables? Acabamos de ver cómo los artículos arqueológicos analizados hablan de cosas diferentes, y cómo para pasar de uno a otro hay que cambiar de palabras, o darles un sentido diferente. Cuando alguien se adscribe al procesualismo adopta el punto de vista de la economía neoclásica (el mismo que, con pocas diferencias, abraza el darwinismo), mientras que si se convierte al marxismo empieza a verlo todo desde una posición que sin dejar de ser económica aparece ya dotada del sentido de crítica moral embebido en el significante "producción". Ambos paradigmas, con todo, coinciden en la misma pretensión cientificista y parten de una idea apriorística del observador como un sujeto universal, neutral e independiente que contempla un pasado objetivo y también universal (Pluciennik 2001: 2). De ahí la necesidad que tienen sus discursos de fijar los significados de los términos teóricos con puntos nodales "fuertes" que apenas admitan deslizamientos del sentido, intentando así ocultar el carácter ideológico de su confianza ciega en una concordancia exacta entre discurso y realidad exterior, entre la teoría y los datos.

En los textos estructuralista y posprocesual, sobre todo en el segundo, se aprecia un abandono de los puntos nodales fuertes y una dispersión mucho mayor del significado: por ejemplo, al hablar de este mismo concepto y de otros relacionados (pensamiento, mente, estructura, simbolismo, ideología) sus autores afirman que unas veces se refieren al ámbito simbólico del pasado y otras al del presente. La mera admisión de que los discursos arqueológicos son hechos desde un cambiante momento actual ya implica la renuncia a un cono- 
cimiento exacto y definitivo de la "realidad" antigua, y una aceptación de que nos hallamos ante una interpretación más entre las varias posibles en cada momento de lo que ocurrió y por qué ocurrió entonces.

Todo este alejamiento progresivo de la cientificidad clásica no implica en absoluto el abandono de lo esencial de la práctica investigadora, la búsqueda de la mayor consonancia posible con la realidad, es decir, de lo que antes se conocía como "objetividad" y "verdad". Lo que ocurre es que a esa verdad la conocemos mucho mejor ahora: sabemos que se presenta en forma de lenguaje y que éste es antes de nada un sistema inestable de diferencias. Aceptar de forma consecuente esa inseguridad intrínseca es cumplir con la máxima ética de la deconstrucción derridiana (Heath 2005: vii): "la firme decisión de dejar sin decidir lo indecidible".

\section{Agradecimientos}

A Alfredo González-Ruibal, Carmen Ortiz y Almudena Hernando por sus útiles comentarios y críticas al texto.

\section{Referencias Bibliográficas}

Ahmad, K. (2006): Metaphors in the language of science? En Gotti y Giannoni 2006: 197-220.

Alcina Franch, J. (1991): La arqueología en España: una revisión crítica de sus planteamientos teóricos. Trabajos de Prehistoria, 48: 13-28.

Anfruns, J.; Dueñas, J.A.; Llobet, E. (eds.) (1988): Corrents tèorics en Arqueologia. Columna, Barcelona.

Bнatia, V.J.; Gotтi, M. (eds.) (2006): Explorations in Specialized Genres. Peter Lang, Berna.

Bosque, I. (2012): Sexismo lingüístico y visibilidad de la mujer. El País, 4 de marzo.

Brown, G.; Yule, G. (2005): Análisis del discurso. Visor Libros, Madrid.

Criado Boado, F. (1989): Megalitos, espacio, pensamiento. Trabajos de Prehistoria, 46: 75-98.

Criado Boado, F. (2012): Arqueológicas. La razón perdida. Bellaterra, Barcelona.

Critchley, S.; Marchart, O. (eds.) (2004a): Laclau. A critical reader. Routledge, Londres.

Critchley, S.; Marchart, O. (2004b): Introduction. En Critchley y Marchart 2004a: 1-13.

Culler, J. (1992): Sobre la deconstrucción. Cátedra, Madrid.

Dennell, R. (1983): European Economic Prehistory. A New Approach. Academic Press, Londres.

DíAz-Andreu, M. (1993): Theory and ideology in archaeology: Spanish archaeology under the Franco régime. Antiquity, 67(254): 74-82.

Díaz-Andreu, M. (2002 [1994]): El pasado en el presente: la búsqueda de las raíces en los nacionalismos culturales en España. Historia de la Arqueología. Estudios (M. Díaz-Andreu), Ediciones Clásicas, Madrid: 121-134.

Doolin, B. (2007): Biotechnology discourse. Discourse Studies, 9(1): 5-8.

Eagleton, T. (1997): Ideología. Una introducción. Paidós, Barcelona.

Escacena, J.L.; García Rivero, D. (2007): Interdemic Selection and Phoenician Priesthood. Darwinian Reflections on the Archaeostronomy of Southern Spain. Theoretical and Methodological Issues in Evolutionary Archaeology: Towards a Unified Darwinian Paradigm (H.J. Muscio y G.E. López, eds.), British Archaeological Reports S1915, Archaeopress, Oxford: 21-30.

Fairclough, N. (1995): Critical Discourse Analysis. The Critical Study of Language. Longman, Londres.

Fernández Martínez, V.M. (1997): Desenterrando la risa: una aproximación a la arqueología y el humor. Complutum, 8: 335-368.

FERnÁNDEZ MARTínez, V.M. (2001): La idea de África en el origen de la prehistoria española: una perspectiva postcolonial. Complutum, 12: 167-184.

Fernández Martínez, V.M. (2006a): Una arqueología crítica. Ciencia, ética y política en la construcción del pasado. Crítica, Barcelona.

FERnÁNDEZ Martínez, V.M. (2006b): Arqueologías críticas: el conflicto entre verdad y valor. Complutum, 17: $191-203$.

FERNÁNDEZ MARTínez, V.M. (2011): Arqueología y hegemonía: la contribución al pensamiento conservador español entre los siglos XIX y XX. Historia, teoria e método da arqueologia. Actas do IV Congresso de Arqueología Peninsular (N. Ferreira Bicho, ed.), Universidade do Algarve, Faro: 281-289. 
Fernández Martínez, V.M.; Ruiz Zapatero, G. (1984): El análisis de territorios arqueológicos: una introducción crítica. Arqueología Espacial (Teruel), 1: 55-71.

Flowerdew, J.; Gott, M. (eds.) (2006): Studies in Specialized Discourse. Peter Lang, Berna.

Foucault, M. (1978): Historia de la sexualidad. 1. La voluntad de saber. Siglo XXI, Madrid.

Franzosi, R. (2004): From Words to Numbers. Narrative, Data, and Social Science. Cambridge University Press, Cambridge.

García Rivero, D. (2004): Prehistoria y evolución: reflexiones sobre la secuencia ecológico-cultural holocénica en el Mediodía ibérico. Spal, 13: 9-34.

Gilman, A. (1995): Recent trends in the archaeology of Spain. The Origin of Complex Societies in Late Prehistoric Iberia (K.T. Lillios, ed.), Ann Arbor: 1-6.

Glynos, J.; Howarth, D. (2007): Logics of Critical Explanation in Social and Political Theory. Routledge, Londres.

Gotti, M.; Giannoni, D.S. (eds.) (2006): New Trends in Specialized Discourse Analysis. Linguistic InsightsStudies in Language and Communication, Peter Lang, Berna.

Griggs, S.; Howarth, D. (2000): New environmental movements and direct action protest: the campaign against Manchester Airport's second runway. En Howarth y otros 2000: 52-69.

Halliday, M.A.K. (2004): The Language of Science. Continuum, Londres.

Heath, S. (2005): Jacques Derrida, 15 July 1930 - 9 October 2004. Critical Quarterly, 47 (1-2): v-viii.

Hodder, I. (1987): La arqueología en la era post-moderna. Trabajos de Prehistoria, 44: 11-26.

Howarth, D. (2000): Discourse. Open University Press, Buckingham.

Howarth, D.; Norval, A.J.; Stavrakakis, Y. (eds.) (2000): Discourse Theory and Political Analysis. Manchester University Press, Manchester.

Howarth, D.; StavraKakis, Y. (2000): Introducing discourse theory and political analysis. En Howarth y otros 2000: 1-23.

Hutson, S. (1998): Strategies for the Reproduction of Prestige in Archaeological discourse. Assemblage, 4 (http:// www.shef.ac.uk/assem/)

JÄGER, S. (2001): Discourse and knowledge: theoretical and methodological aspects of a critical discourse and dispositive analysis. En Wodak y Meyer 2001: 32-62.

Joyce, R. (2002): The Languages of Archaeology. Dialogue, Narrative and Writing. Blackwell, Oxford.

Koskela, M. (1997): Inference in Science and Popular Science. Culture and Styles in Academic Discourse (A. Duszak, ed.), Mouton, Berlin: 343-355.

Kunn, T. (1971): La estructura de las revoluciones cientificas. Fondo de Cultura Económica, México.

LaClau, E. (1992): Prefacio. En Žižek 1992: 11-19.

LaClau, E. (1993): Nuevas reflexiones sobre la revolución de nuestro tiempo. Nueva Visión, Buenos Aires.

LaClau, E. (2002): Misticismo, retórica y politica. Fondo de Cultura Económica, Buenos Aires.

Laclau, E.; Mouffe, C. (1987): Hegemonía y estrategia socialista. Hacia una radicalización de la democracia. Siglo XXI, México.

Lakoff, G.; Johnson, M. (2001): Metáforas de la vida cotidiana. Cátedra, Madrid.

Martin, J.R.; Wodak, R. (eds.) (2003): Re/reading the Past: Critical and Functional Perspectives on Time and Value. Benjamins, Ámsterdam.

Martínez Navarrete, M.I. (1989): Una revisión crítica de la prehistoria española. La Edad del Bronce como paradigma. Siglo XXI, Madrid.

Martínez Navarrete, M.I. (ed.) (1993): Teoría y práctica de la prehistoria: perspectivas desde los extremos de Europa (Reunión hispano-rusa de prehistoriadores). Universidad de Cantabria, Santander.

Martínez Navarrete, M.I. (2002): Archaeological thought and practice in Spain (1939-2000). Archäologien Europas/Archaeologies of Europe (P. F. Biehl, A. Gramsch y A. Marciniak, eds.), Wasmann Münster, Berlin: 361-401.

McDonald, S.P. (1989): Data-driven and conceptually driven academic discourse. Written Communication, 6(4): 411-435.

McGuire, R.H.; NAVARrete, R. (1999): Entre motocicletas y fusiles: las arqueologías radicales anglosajona e hispana. Revista do Museu de Arqueologia e Etnologia (Sao Paulo), suplemento 3: 181-199. 
Norval, A.J. (1996): Deconstructing Apartheid Discourse.Verso, Londres.

OliveIRA, J.M. DE; PAGANo, A.S. (2006): The research article and the science popularization article: a probabilistic functional grammar perspective on direct discourse representation. Discourse Studies, 8(5): 627-646.

Phuong Dzung Pно (2008): Research article abstracts in applied linguistics and education technology. Discourse Studies, 10(2): 231-250.

PlucienniK, M. (1999). Archaeological Narratives and other Ways of Telling. Current Anthropology, 40(5): 653678.

Pluciennik, M. (2001): Introduction. The responsibilities of archaeologists. The Responsibilities of Archaeologists. Archaeology and Ethics (M. Pluciennik, ed.), Lampeter Workshop in Archaeology, 4, British Archaeological Reports, International Series 981, Oxford: 1-8.

RUDEBECK, E. (1996): Heroes and tragic figures in the transition to the Neolithic: Exploring images of the human being in archaeological texts. Journal of European Archaeology, 4: 55-86.

Ruiz Rodríguez, A. (1993): Panorama actual de la arqueología española. En Martínez Navarrete 1993: 307-323.

Ruiz Zapatero, G. (1993): La organización de la arqueología en España. En Martínez Navarrete 1993: 45-76.

Ruse, M. (2009): Darwin y la filosofía. Teorema, 28(2): 15-33.

Sillar, B. (ed.) (1992): Digging for a laugh. Archaeology and Humour. Archaeological Review from Cambridge, $11(2)$.

StaVRaKaKis, Y. (2000): On the emergence of Green Ideology: the dislocation factor in Green politics. En Howarth y otros 2000: 100-118.

Thomas, J. (1993): Discourse, totalization and 'The Neolithic'. En Tilley 1993a: 357-394.

TILley, C. (1989a): Discourse and power: the genre of the Cambridge inaugural lecture. Domination and Resistance (D. Miller, M. Rowlands, C. Tilley, eds.), Unwin Hyman, Londres: 41-62.

Tilley, C. (1989b): Archaeology as socio-political action in the present. Critical Traditions in Contemporary Archaeology. Essays in the Philosophy, History and Socio-Politics of Archaeology (V. Pinsky, A. Wylie, eds.), Cambridge University Press, Cambridge: 104-116.

Tilley, C. (1990): On modernity and archaeological discourse. Archaeology after Structuralism. Post-structuralism and the Practice of Archaeology (I. Bapty, T. Yates, eds.), Routledge, Londres: 128-152.

Tilley, C. (ed.) (1993a): Interpretative Archaeology. Berg, Providence.

Tilley, C. (1993b): Prospecting archaeology. En Tilley 1993a: 395-416.

TilLEy, C. (1999): Metaphor and Material Culture. Blackwell, Oxford.

VAN DıJK, T. (2009): Discurso y poder: contribuciones a los estudios críticos del discurso. Gedisa, Barcelona.

Ventola, E.; Mauranen, A. (1992): Non-native writing and native revising of scientific articles. Functional and Systemic Linguistics: Approaches and Uses, Mouton, Berlín: 457-492.

Vicent, J. (1994): Perspectivas de la teoría arqueológica en España. VI Congreso Hispano-Ruso de Historia, Fundación Cultural Banesto-CSIC, Madrid: 215-223.

VICENT, J. (1998): La prehistoria del modo tributario de producción. Hispania, 58(3): 823-839.

VV.AA. (1984): Primeras jornadas de metodología de la investigación prehistórica. Ministerio de Cultura, Madrid.

Wetherell, M. (2001): Debates in discourse research. Discourse Theory and Practice. A Reader (Wetherel, M.; Taylor, S.; Yates, S.J., eds.), Sage, Londres: 380-399.

WhiтE, H. (1992): Metahistoria: la imaginación histórica en la Europa del siglo XIX. Fondo de Cultura Económica, México.

WoDAK, R. (2001): What is CDA about. A summary of its history, important concepts and its developments. En Wodak y Meyer 2001: 1-13.

Wodak, R.; Meyer, M. (eds.) (2001): Methods of Critical Discourse Analysis. Sage, Londres.

Worthington, F.; Hodgson, J. (2005): Academic labour and the politics of quality in higher education. Critical Quarterly, 47(1-2): 96-110.

ŽıžEK, S. (1992): El sublime objeto de la ideología. Siglo XXI, México.

ŽıžEK, S. (1994): Introduction. The spectre of ideology. Mapping Ideology (S. Žižek, ed.), Verso, Londres: 1-33. 